\title{
PLYMOUTH
}

Title: Effects of clothing perception on psychological factors and tactical intentions in fencing.

Author(s): Aldous-Granby, James; McCormick, Alister

Copyright, publisher and additional information: This is an Accepted Manuscript of an article published by Taylor \& Francis in International Journal of Sport and Exercise Psychology on 19/09/2018, available online: http://www.tandfonline.com/10.1080/1612197X.2018.1519840

DOI: https://doi.org/10.1080/1612197X.2018.1519840

Reference: Aldous-Granby, James and McCormick, Alister (2018) Effects of clothing perception on psychological factors and tactical intentions in fencing. International Journal of Sport and Exercise Psychology. 
Effects of Clothing Perception on Psychological Factors and Tactical Intentions in Fencing

James Aldous-Granby and Alister McCormick

School of Sport, Health \& Wellbeing, Plymouth Marjon University, Derriford Road, Plymouth, PL6 8BH, United Kingdom.

Correspondence concerning this article should be addressed to James Aldous-Granby. Email: j.aldous.granby@gmail.com 


\section{Effects of Clothing Perception on Psychological Factors and Tactical Intentions in Fencing}

Research shows body language can affect opponent perception, but it presents inconsistencies for clothing. The consequences of clothing perception have received little attention. This study examined if clothing can affect perception in a sporting context and examined the effects of this change. Fencers $(N=63)$ completed a questionnaire displaying two conditions of a fencing opponent: an international condition and a club condition. Participants' judgements of the opponent, self-efficacy, outcome expectations, locus of control, and tactical intentions were measured. Results showed participants perceived the international opponent to be of a higher level $(p<.001)$ and ability $(97.4 \%, p<$ $.001)$, and they judged them more favourably $(67.8 \%, p<.001)$. Self-efficacy ($16 \% \pm 19, p<.01)$ and outcome expectations $(-26.7 \%, p<.001)$ decreased while locus of control became more external $(p<.001)$ against the international opponent. Participants intended to be less attacking and less assertive during the first hit and throughout the match against the international opponent $(p<.025)$. These results show that clothing can affect opponent perception within sport, impacting key psychological performance factors and tactical intentions. This study highlights the need for further investigation into person perception in sport, especially the mechanisms causing less attacking and assertive behaviour against perceived high-level opponents.

Keywords: locus of control; outcome expectations; self-efficacy; tactics 


\section{Introduction}

Nonverbal communication, such as clothing and body language, has been shown to be an important information source within person perception, which can affect social interactions (Knapp, Hall, \& Horgan, 2012). As sporting encounters can be considered a distinct sub-category of social interaction, clothing and body language could affect the outcome of this social interaction.

Within a sporting context, research suggests that athletes use schema-driven processing when perceiving opponents (Greenlees, 2007). This is where the athlete assigns their opponent, based on their perception of them, to a category in order to make judgements and expectations of the opponent. Warr \& Knapper's (1968) model provides a comprehensive theoretical schema-driven model of how an individual attends, processes, makes judgements, and makes expectations of another individual. From this model, cognitive biases can be predicted, which are shown throughout sporting literature. Possibly the most influential of these biases is confirmation bias. Greenlees, Dicks, Holder, and Thelwell (2007) evidenced this in a sporting context by showing participants videos of a target passing a football in either ascending or descending order of success. Participants who viewed the videos in descending order rated the target more favourably than those who viewed the videos in ascending order, suggesting that the information perceived first was more influential in forming their judgements.

How an athlete perceives their opponent is important because research suggests that it will affect how they perform. Much of this research is on self-efficacy. For example, Nelson and Furst (1972) showed objectively-weaker participants won arm wrestles $83 \%$ of the time when both parties perceived the subsequent winner to be stronger. In addition, Weinberg and colleagues (Weinberg, Gould, Yukelson, \& Jackson, 1981; Weinberg, Yukelson, \& Jackson, 1980) showed that participants, who 
were told their opponent in a muscular endurance task was superior at the task, performed significantly worse than when they believed themselves to be superior at the task. These studies show that opponent perception can influence performance and suggests that this may occur by affecting self-efficacy.

Despite research showing that opponent perception can affect performance, there is a paucity of literature examining what information affects perception. Some researchers (Buscombe, Greenlees, Holder, Thelwell, \& Rimmer, 2006; Greenlees, Bradley, Holder, \& Thelwell, 2005; Greenlees, Buscombe, Thelwell, Holder, \& Rimmer 2005) have examined the impact of body language and clothing as forms of non-verbal behaviour. Greenlees, Bradley, et al. (2005) measured the difference between participants' outcome expectations against an opponent and judgements of an opponent across four conditions, involving positive/negative body language and sport specific/general sports clothing. They found both positive body language and sportspecific clothing reduced participants' outcome expectations. Only body language affected judgements, with positive body language eliciting more favourable judgements of sporting ability. No interaction effect between body language and clothing was found.

Using the same conditions, Greenlees, Buscombe, et al. (2005) measured outcome expectations and judgements. They likewise found that body language significantly affected outcome expectations and judgements, and it appeared that outcome expectations decreased due to the more favourable judgement of the opponent's perceived ability. However, they did not find any effect for clothing. Using the same procedures, Buscombe et al. (2006) measured outcome expectations but measured rating of opponent ability instead of judgements. They again reported effects for body language for both variables but no main effects for clothing. Follow-up 
analyses, however, revealed that when displaying negative body language, opponents were rated more favourably when they were wearing general sports clothing than sportspecific clothing. These results are contrary to Greenlees, Bradley, et al. (2005). Although these three studies show that body language can affect outcome expectations, opponent judgements, and ratings of opponent ability, the role of clothing in opponent perception remains unclear.

Despite the presented inconsistencies, it is clear that clothing does influence person perception in other social interactions (Knapp et al., 2012). Greenlees, Leyland, Thelwell, \& Filby (2008) examined the effects of red and white uniform colour on perception of penalty takers and found that penalty takers were perceived to possess characteristics that were more positive in nature when they were wearing red. In addition, Hill and Barton (2005) showed human performance may be decreased by an opponent wearing red. In combat sports during the 2004 Athens Olympic Games, a higher proportion of victories went to athletes wearing red, compared to blue. Although there was an overall effect, only bouts of similar ability were affected, suggesting the influence of wearing red was enough to tip the match. A similar analysis (Hill \& Barton, 2005) of the UEFA European Championship 2004 football competition also showed that football teams had better results when playing in red. While these results seem to show clothing affecting opponent perception and performance, colour on its own is known to affect perception (Little \& Roberts, 2012). Therefore, while changing the colour of clothing may be a method of manipulating perception, the same results may be achieved through other methods of colour change. Whether clothing, as a separate construct, affects perception is not answered by this research.

A limitation of all the research so far presented is it does not consider the effects of perception within more complex sporting contexts. That it does not consider how 
changes in perception will affect behaviour towards the opponent (i.e. tactics). Given sport can be considered a social interaction (Knapp et al., 2012), it seems an oversight to have not considered how perception affects the interaction.

Olympic fencing was chosen as the context for the current study because it is suggested that tactics are the most important determinant of victory; it is the selection of the action and its execution at the right time and speed that determines success (Czajkowski, 2009; Patócs et al., 2016; Poliszczuk, Poliszczuk, Dạbrowska-Perzyna, \& Johne, 2013). Therefore, while physical attributes are important (to perform an action at the correct speed), coaches and athletes should understand the psychology of fencing and how it is affected. How a fencer perceives their opponent is theorised to influence their behaviour during the fight (Greenlees, 2007).

This study examined the effects of clothing (Team Great Britain [GB] kit versus club kit) on person perception, performance-related psychological factors, and intended behaviour in sport. Specifically, it examined the effects of clothing on person perception within Olympic fencing, measuring its effect on perception of ability as well as the judgements that participants made about their opponent. It also examined the effects of this change in clothing (and potential change in perception) on self-efficacy, outcome expectations, and locus of control, which are performance-related psychological factors. Finally, this study examined the effects of the change in clothing (and the potential changes in perception and performance-related psychological factors) on intended behaviour, measured as intended tactics. It was hypothesised that participants would perceive a fencer wearing Team GB kit as a higher-level fencer with higher ability, compared to a fencer wearing club kit. It was also hypothesised that participants would have lower self-efficacy and outcome expectations, have a more external locus of control, and intend to use less aggressive and less assertive tactics against the Team GB 
fencer. The hypothesis of tactical intentions was made from Langer's (1975) classic study suggesting behaviour is less aggressive/assertive when an opponent is perceived more highly (dressed more smartly and acting more confidently in Langer's (1975) study).

\section{Method}

A hypothetical research scenario was used to achieve greatest participant recruitment. This method was advantageous because it also allowed control of other influential variables, such as body language. Therefore, an online questionnaire was distributed through social media and personal contacts. British Fencing forwarded the questionnaire to all registered coaches in the UK. Sixty-three people who identified as competitive fencers (individuals participating in fencing to compete), coaches, or both completed the survey (mean national ranking of those 27 ranked $=37.9, S D=62.4,36$ unranked, seven ranked $1^{\text {st }}$, 15 ranked in the top 10). Figure 1 displays participant distribution by gender $($ male $=47$, female $=16)$, primary weapon $($ epee $=22$, foil $=19$, sabre $=22$ ) and competitive level (none $=5$, county $=11$, university $=11$, national $=6$, commonwealth $=6$, international $=24$ ).

Figure 1: Participant distribution by gender, primary weapon and competitive level.

Two conditions, using one model, were created in an online survey. The model was a white-European female international fencer aged 18. Due to the nature of fencing clothing, the model's facial appearance was obscured, meaning it could not affect perception. The model's body language was neutral to avoid participants' perception affecting results. Body language was similar between the conditions. Photographs were used to portray the conditions, removing the possibility of the model's movements affecting perception. As the weapons used within Olympic fencing could be considered distinct sports, they may affect opponent perception. Therefore, conditions were 
designed to be weapon ambiguous, consisting of a mask, jacket, breeches, socks and shoes.

The first condition was designed to represent a club-level fencer ("club condition") (Figure 2). The model wore kit taken from communal kit (mask, jacket, and breeches) of a university fencing club, plain socks and their trainers. The second condition was designed to represent an international-level fencer ("international condition") (Figure 2). The model wore their own Team GB kit, including painted mask, striped jacket, striped breeches, British Fencing socks and fencing-specific shoes.

Figure 2: Left, photo used to present the club condition. Right, photo used to present the international condition

The survey was created in Google Forms, and it took approximately 10 minutes to complete. Participants first provided their informed consent, and they then completed a personal information section, the club condition, and finally the international condition. While completing the conditions, at the beginning of each section participants were again shown the photo. This condition order was chosen because it was anticipated that more participants would identify with the club condition, making it closer to a baseline reading. Therefore, changes were measured from the club to international conditions.

Participants were required to provide personal information in the following order: identification as a competitive fencer, age, nationality, years fenced for, years competed in fencing for, gender competed as, age group British Fencing national ranking, highest age group national ranking of any nation, highest competitive level, described level and primary weapon. Competitive level was measured here and as a judgement, using levels. The levels were none, county, university, national, commonwealth, and international, in ascending order. These levels measured the 
highest level at which participants had competed. Described level, used here and as a judgement, measured participant's perception of fencing ability, using the following levels: beginner, intermediate, competent, advanced, and elite.

Self-efficacy was measured first after viewing the relevant image. Self-efficacy scales were constructed according to Bandura's (2006) recommendations. Specifically, participants were asked to answer how they felt then and not to generalise, items were worded as statements of capability using the phrase "I can" and items were designed to accurately portray aspects of Olympic fencing. However, due to the nature of the Google Forms, a 0-10 scale was used, as opposed to the 0-100 scale preferred, and intermediate degrees of assurance (moderately certain) were not provided for each item.

Ten items were designed to create the self-efficacy scale: I can come up with a winning plan; I can execute my plan well; I can attack well; I can execute a good attack; I can defend well; I can choose the right preparation; I can execute my preparation well; I can execute good blade-work; I can execute good footwork; and I can remain calm. Participants were asked to rate their confidence that they could do each item, in a fight against the pictured opponent, on a scale of 0-10 where 0 was "cannot do at all" and 10 was "highly certain can do". Participants' responses for each item were summed to create an individual self-efficacy score for each condition.

Participants next completed the outcome expectations grid. The grid was designed using the recommendations of Feltz and Chase (1998). It consisted of the 10 possible outcomes for the participant fighting the model 10 times, one victory, two victories, and so on up to 10 of 10 victories. Participants were asked to rate their confidence, from 0 to 10 , that they could achieve each of these outcomes. Participants' scores were then summed to provide an individual outcome expectation for each condition. 
Participants next provided their perceived locus of control, measured using a 10point Likert scale. Participants were asked to rate to what degree they thought their actions would dictate the outcome of the match where 1 was "not at all" and 10 was "completely".

Participants were next asked about their tactical intentions against the model, both for the first hit and for the match. As the three weapons can be considered distinct sports, it would be impossible to measure tactical intentions in terms of specific movements. Therefore, how attacking/defensive and how assertive/reactive the participants intended to be were measured using 10-point semantic differential scales. Assertive/reactive was chosen as Langer (1975) suggests that individuals competing against a perceived high level opponent will behave less assertively and it is relevant to tactical strategies Attacking/defensive was chosen as it is an important piece of information available to a fencer when creating a tactical strategy.

Participants next answered questions designed to measure judgements they made about the model. Participants first rated their opponent's ability on a 10-point Likert scale, where 1 was "very poor" and 10 was "very good". Participants then rated their opponents' level (beginner to elite).

Finally, participants rated the model on 10 dimensions relevant to Olympic fencing performance, reflecting the model's readiness, psychological state and ability, on 10-point semantic differential scales. The dimensions used, in order, were: passive/aggressive, non-competitive/competitive, reactive/assertive, not talented/very talented, mentally-fragile/mentally-tough, unfit/very fit, very slow/very fast, unintelligent/very intelligent, unprepared/very prepared, unconfident/very confident. Participant's scores were then summed to create an individual opponent judgement score, ranging from 10 to 100 . 
Where responses were incomplete or included theoretically-implausible answers that represented misunderstanding the question (reporting higher confidence in winning more times out of 10 , than previously reported for winning less times out of 10), they were excluded from analyses. Participant responses for self-efficacy, outcome expectations, and aspect judgements were only included when all 10 responses were complete and theoretically plausible. To test for significant differences between conditions, either a paired sample $t$-test (for continuous data) or Wilcoxon signed-rank test (for ordinal or nominal data) were used. To test for correlations between variables, either a Pearson's product-moment correlation (when both variables were continuous) or a Spearman's rank-order correlation (when one or more variables were ordinal or nominal) were used. To test for significant differences of between-subject variables (e.g. gender), a generalised linear model was used, as all the demographic variables were ordinal or nominal.

\section{Results}

\section{Opponent Perception}

Opponent perception was measured using three variables, rating of opponent ability out of $10(n=61)$, judgements of the opponent $(n=55)$ and described opponent level $(n=$ 63). Paired sample $t$-tests revealed the mean perception of opponent ability out of 10 increased by $3.72(97.4 \%, \mathrm{SD}=2.30)$ from the club condition $(M=3.82, S D=2.10)$ to the international condition $(M=7.54, S D=1.51), t(60)=12.7, p<.001, d=1.62$. Mean sum judgements of the opponent increased by 29.7 out of $100(67.8 \%, S D=16.7)$ from the club condition $(M=43.8, S D=13.8)$ to the international condition $(M=73.5, S D=$ 11.6), $t(54)=13.2, p<.001, d=1.78$. Follow-up analyses revealed all individual aspect judgements significantly increased $(p<.001)$. A Wilcoxon signed-rank test revealed 
perception of described level significantly increased, with 60 of 63 participants perceiving the international condition higher ( 3 ties, 0 negatives). The modal perception for the club condition was "beginner", and "advanced" for the international condition ( $z$ $=6.48, p<.001)$. The spread of this data can be viewed in Figure 3. These results show a clear difference in opponent perception over the two conditions, demonstrating that clothing affected person perception.

Figure 3: Participants' $(n=63)$ perception of a fencing opponent's level (beginner, intermediate, competent, advanced, and elite) over two modelled clothing conditions of communal club kit (club condition) and Team Great Britain kit (international condition).

\section{Outcome Expectations}

Outcome expectations was the variable most affected by excluded responses. Only 38 (60.3\%) participants fully completed the relevant question correctly (25 excluded). Paired sample $t$-tests revealed participants' perceived outcome expectations decreased by 21.8 out of $100(26.7 \%$ decrease, $S D=24.1)$ from the club condition $(M=81.6, S D$ $=23.7)$ to the international condition $(M=59.8, S D=31.8), t(37)=5.57, p<.001, d=$ 0.90), demonstrating that clothing decreased outcome expectations. Greater increases in participants' perceptions of opponent level $\left(r_{s}(36)=-0.39, p=.15\right)$ and judgements of opponent ability $\left(r_{s}(53)=-0.30, p=.071\right)$ were not significantly related to decrements in outcome expectations. Sum of aspect judgements $(r(33)=-0.48, p=.004)$ was significantly related.

\section{Locus of Control}

When viewing the international condition, participants $(n=63)$ perceived a more external locus of control, with 38 participants reporting lower scores (17 ties, 8 
increases). A Wilcoxon signed-rank test determined there was a significant median decrease (1) in scores out of 10 , when subjects viewed the international condition ( $M d n$ =7), compared to the club condition $(M d n=9), z=-5.165, p<.001$, suggesting that international clothing reduced perceptions of control. Greater increases in participants' perceptions of opponent level $\left(r_{s}(61)=-0.51, p<.001\right)$, judgements of opponent ability $\left(r_{s}(59)=-0.36, p=.005\right)$, and the sum of aspect judgements $\left(r_{s}(53)=-0.52, p<.001\right)$ were associated with greater shifts towards a more external locus of control.

\section{Self-Efficacy}

A paired sample $t$-test revealed that participants' $(n=55)$ self-efficacy (out of 100) decreased by $15.3 \%$ from the club condition $(M=82.3, S D=12.2)$ to the international condition $(M=69.7, S D=20.0), t(54)=6.06, p<.001, \mathrm{~d}=0.82$, suggesting that international clothing reduced self-efficacy. Greater increases in participants' perceptions of opponent level $\left(r_{s}(53)=-0.59, p<.001\right)$, judgements of opponent ability $\left(r_{s}(53)=-0.32, p=.018\right)$, and the sum of aspect judgements $\left(r_{s}(53)=-0.49, p<0.001\right)$ were associated with greater decreases in self-efficacy.

\section{Tactical Intentions}

Four measures of tactical intentions were recorded, first hit offensiveness, first hit assertiveness, match offensiveness, and match assertiveness. In the international condition, participants $(n=62)$ reported they intended to be more defensive (less attacking) for the first hit, with 34 participants reporting more defensive scores (17 ties, 11 more attacking). A Wilcoxon signed-rank test determined that there was a statistically significant median decrease (1) when subjects viewed the club condition $(M d n=7)$ compared to the international condition $(M d n=7), z=-2.872, p=.004$. Participants $(n=62)$ also reported that they intended to be more reactive (less assertive) 
for the first hit in the international condition, with 29 participants reporting more reactive scores (21 ties, 12 more assertive). A Wilcoxon signed-rank test determined that there was a statistically significant median decrease (0) when subjects viewed the club condition $(M d n=8)$ compared to the international condition $(M d n=7), z=-2.48$, $p=.013$

For the match, participants $(n=62)$ reported an intent to be more defensive in the international condition, with 36 reporting more defensive scores (17 ties, 9 more attacking). A Wilcoxon signed-rank test determined that there was a statistically significant median decrease (1) when subjects viewed the club condition $(M d n=7)$ compared to the international condition $(M d n=6), z=-3.92, p<.001$. Participants $(n=$ 62) also reported an intent to be more reactive in the international condition, with 31 reporting more reactive scores (17 ties, 14 more attacking). A Wilcoxon signed-rank test determined that there was a statistically significant median decrease (5) when subjects viewed the club condition $(M d n=8)$ compared to the international condition $(M d n=7), z=-3.02, p=.003)$.

A series of correlation analyses suggested that as opponent perception increased, opponents intended to fence more defensively and more reactively. Moderate correlations were found between change in opponent ability rating out of 10 , change in intended match offensiveness $\left(r_{s}(60)=-0.297, p=.021\right)\left(r_{s}(61)=-0.347, p=.006\right)$ and change in intended match assertiveness $\left(r_{s}(61)=-0.347, p=.006\right)$. Correlations for intended first hit intended offensiveness $\left(r_{s}(61)=-0.081, p=.536\right)$ and assertiveness $\left(r_{s}(61)=-0.091, p=.483\right)\left(r_{s}(61)=-0.081, p=.536\right)$ were not significant. Moderate correlations were also found between change in perceived opponent level, change in intended $1^{\text {st }}$ hit offensiveness $\left.r_{s}(62)=-0.307, p=.015\right)$, change in intended $1^{\text {st }}$ hit assertiveness $\left(r_{s}(62)=-0.387, p=.002\right)$ and change in intended match offensiveness $\left(r_{s}\right.$ 
$(62)=-0.339, p=.007)$. The correlation to match assertiveness was not significant $\left(r_{s}\right.$ $(63)=-0.228, p=.072$ ). Finally, weak to moderate correlations were found between change in aspect judgements, change in intended $1^{\text {st }}$ hit assertiveness $\left(r_{s}(55)=-0.308, p\right.$ $=.022)$, change in intended match offensiveness $\left(r_{s}(55)=-0.442, p=.001\right)$ and change in intended match assertiveness $\left(r_{s}(55)=-0.399, p=.003\right)$. The correlation to intended $1^{\text {st }}$ hit offensiveness was not significant $\left(r_{s}(55)=-0.184, p=.179\right)$.

\section{Discussion}

This study had three aims. First, it examined the effects of clothing on person perception within Olympic fencing. Perception of the opponent was shown to change between the club to international condition. The international condition was perceived as higher ability and competitive standard. Second, it examined the effects of this change in clothing and perception on the performance-related psychological factors self-efficacy, outcome expectations, and locus of control. The psychological performance factors were shown to change, with these changes being related to the magnitude of changes in perception. From the club to international condition, outcome expectations decreased, locus of control became more external, and self-efficacy decreased. Finally, it examined effects on intended behaviour, measured as tactical intentions. Tactical intentions were shown to change across the two conditions, with participants intending to be less attacking and assertive against the international condition than the club condition, for both the first hit and the match.

These results support the findings of research in other social interactions that clothing can affect person perception (Knapp et al., 2012). Although they contradict the findings of Greenlees, Buscombe, et al. (2005), who found that clothing did not affect opponent perception in a sporting context, they are supported by Buscombe et al. (2006) and Greenlees, Bradley, et al. (2005), whose results suggest clothing can affect 
perception in this context. The results of this study support existing research (Buscombe et al., 2006; Greenlees, Bradley, et al., 2005; Greenlees, Buscombe, et al., 2005; Greenlees et al., 2008) that shows increased opponent perception decreases outcome expectations. Similar-sized changes in opponent judgments and outcome expectations between studies suggest that the changes in perception caused by clothing and its effects on outcome expectations are comparable to those caused by body language.

The more external locus of control that accompanied a more advanced opponent perception reported in the current study supports the findings of the classic study by Langer (1975), where college students betted less against more confident and better dressed opponents. In Langer's study, however, an illusion of control was measured using a game of chance. In the present study, a difference in ability would affect the amount of control a fencer had in a fight, as a more competent fencer would be able to control the fight.

The decrease in self-efficacy that accompanied increased opponent perception reported in the current study supports existing literature (Furley \& Schweizer, 2014; Nelson \& Furst, 1972; Weinberg, Gould, \& Jackson, 1979; Weinberg et al., 1981, 1980). This literature showed a decrease in muscular performance caused by changes in opponent perception. The changes in perceptions caused by clothing in the current study may cause similar effects, meaning that opponent clothing may affect the entire sporting interaction.

The changes in tactical intentions reported cannot be compared to any previous research to the researchers' knowledge. The theoretical implications of decreased intended offensiveness and assertiveness against a perceived high-level opponent warrants further research. Practical implications can be drawn, however. Fencers should try to understand how they are perceived by their opponents (e.g. through observation 
by teammates and coaches). From this study, they may then be able to predict their opponent's tactics and counter them accordingly. This study and other studies (Buscombe, Greenlees, Holder, Thelwell, \& Rimmer, 2006; Greenlees, Bradley, Holder, \& Thelwell, 2005; Greenlees, Buscombe, Thelwell, Holder, \& Rimmer 2005) also suggest clothing and body language could also be used intentionally to affect an opponent's confidence and tactics. Applied research in the field (e.g., in training environments) could further explore the applied value of research in this area.

In conclusion, this study has shown that clothing, similarly to body language, can affect opponent perception and subsequently outcome expectations, self-efficacy, and locus of control. These changes have been linked with changes in intended tactical behaviour. It appears that what an opponent wears can have psychological effects on an athlete, which has the potential to influence performance.

\section{References}

Bandura, A. (2006). Guide for constructing self-efficacy scales. In F. Pajares \& T. Urdan (Eds.), Self-efficacy beliefs of adolescents (pp. 307-337). Greenwich, CT: Information Age. https://doi.org/10.1017/CBO9781107415324.004

Buscombe, R., Greenlees, I., Holder, T., Thelwell, R., \& Rimmer, M. (2006). Expectancy effects in tennis: the impact of opponents' pre-match non-verbal behaviour on male tennis players. Journal of Sports Sciences, 24, 1265-1272. https://doi.org/10.1080/02640410600598281

Czajkowski, Z. (2009). Tactics in fencing - preparatory actions. Studies in Physical Culture and Tourism, 16, 371-377.

Feltz, D., \& Chase, M. (1998). The measurement of self-efficacy and confidence in sport. In J. Duda (Ed.), Advances in sport and exercise psychological measurement (pp. 65-80). Morgantown, WV: Fitness Information Technology.

Furley, P., \& Schweizer, G. (2014). "I'm pretty sure that we will win!": The influence of score-related nonverbal behavioral changes on the confidence in winning a basketball game. Journal of Sport \& Exercise Psychology, 36, 316-20. https://doi.org/10.1123/jsep.2013-0199

Greenlees, I. (2007). Person perception in sport. In S. Jowett \& D. Lavallee (Eds.), Social psychology in sport (pp. 195-208). Champaign, IL: Human Kinetics. 
Greenlees, I., Bradley, A., Holder, T., \& Thelwell, R. (2005). The impact of opponents' non-verbal behaviour on the first impressions and outcome expectations of tabletennis players. Psychology of Sport and Exercise, 6, 103-115. https://doi.org/10.1016/j.psychsport.2003.10.002

Greenlees, I., Buscombe, R., Thelwell, R., Holder, T., \& Rimmer, M. (2005). Impact of opponents' clothing and body language on impression formation and outcome expectations. Journal of Sport \& Exercise Psychology, 27, 39-52. https://doi.org/10.1123/jsep.27.1.39

Greenlees, I., Dicks, M., Holder, T., \& Thelwell, R. (2007). Order effects in sport: Examining the impact of order of information presentation on attributions of ability. Psychology of Sport and Exercise, 8, 477-489. https://doi.org/10.1016/j.psychsport.2006.07.004

Greenlees, I., Leyland, A., Thelwell, R., \& Filby, W. (2008). Soccer penalty takers' uniform colour and pre-penalty kick gaze affect the impressions formed of them by opposing goalkeepers. Journal of Sports Sciences, 26(6), 569-576. https://doi.org/10.1080/02640410701744446

Hill, R. a., \& Barton, R. a. (2005). Psychology: red enhances human performance in contests. Nature, 435, 293. https://doi.org/10.1038/435293a

Knapp, M., Hall, J., \& Horgan, T. (2012). Nonverbal communication in human interaction (8th ed.). Boston, MA: Cengage.

Langer, E. J. (1975). The illusion of control. Journal of Personality and Social Psychology, 32, 311-328. https://doi.org/10.1037/0022-3514.32.2.311

Little, A. C., \& Roberts, C. S. (2012). Evolution, appearance, and occupational success. Evolutionary Psychology, 10, 782-801. https://doi.org/10.1177/147470491201000503

Nelson, L., \& Furst, M. (1972). An objective study of the effects of expectation on competitive performance. Journal of Psychology, 81, 69-72. https://doi.org/10.1123/jsp.3.4.345

Nowacki, M. (2006). The Essence and Importance of sence of Timing in Fencing. Studies in Physical Culture and Tourism, 13(1), 49-58.

Patócs, Á., Melia, L., Kovács, S., Fózer-selmeci, B., Révész, L., \& Tóth, L. (2016). Reactive stress tolerance and personality characteristics of Hungarian elite fencers. Cognition Brain Behavior. An Interdisciplinary Journal, X20, 171-184.

Poliszczuk, T., Poliszczuk, D., Dạbrowska-Perzyna, A., \& Johne, M. (2013). Asymmetry of complex reaction time in female épée fencers of different sports classes. Polish Journal of Sport and Tourism, 20, 25-29. https://doi.org/10.2478/pjst-2013-0003

Warr, P., \& Knapper, C. (1968). The perception of people and events. London, England: John Wiley \& Sons.

Weinberg, R., Gould, D., \& Jackson, A. (1979). Expectations and performance: An emperical test of Bandura's self-efficacy theory. Journal of Sport Psychology, 1, 320-331. https://doi.org/10.1123/jsp.1.4.320

Weinberg, R., Gould, D., Yukelson, D., \& Jackson, A. (1981). The effect of preexisting and manipulated self-efficacy on a competitive muscular endurance task. Journal 
of Sport Psychology, 4, 345-354. https://doi.org/10.1123/jsp.3.4.345

Weinberg, R., Yukelson, D., \& Jackson, A. (1980). Effect of public and private efficacy expectations on competitive performance. Journal of Sport Psychology, 2, 340349. https://doi.org/10.1123/jsp.2.4.340 